\title{
Circo e teatro: a construção da cena nacional argentina
}

\author{
André Carreira
}

relação entre o circo e o teatro é um elemento chave na história do teatro argentino, não apenas nos momentos da fundação de um teatro nacional, mas também pela persistência de traços dessa influência em espetáculos que se apresentam atualmente no país. Ainda cabe destacar que os próprios artistas reconhecem o modelo do circo criollo como berço da teatralidade porteña.

$\mathrm{Na}$ realidade, para ser mais preciso, seria apropriado fazer referência à influência do circo no "teatro rioplatense", já que o eixo Buenos Aires/Montevidéu constituiu, nos séculos XVIII e XIX, uma zona na qual as companhias circularam de forma intensa, indo permanentemente de uma à outra margem do Rio de La Plata. Segundo as circunstâncias do momento político, cruzar o Rio sempre foi uma condição fundamental para a sobrevivência das companhias, uma vez que, ao trabalhar em ambas as cidades, era possível organizar temporadas mais duradouras e evitar os eventuais problemas com os governos autocráticos de um período de crises.

$\mathrm{Na}$ segunda metade do século XVIII, Buenos Aires, apesar de se firmar como Capital do Vice-Reino, crescia lentamente, contando com apenas 27.000 habitantes. A pequena cidade observava um crescimento significativo das diversōes públicas quando, em 1757, foi inaugurada sua primeira sala estável, o Teatro de Operas y Comedias, que funcionou por apenas um ano. Em 1783, o Vice-Rei Vértiz sugeriu a instalação de uma sala de espetáculos, com o fim de prover aos cidadãos "diversão să". Como conseqüência, foi inaugurada, em 1783, a Casa de Comedias, popularmente conhecida como o Teatro de La Ranchería, uma construção de adobe com teto de palha que constituiu a primeira sala teatral pública da cidade.

Mesmo antes do surgimento de La Rancheria, que desapareceria poucos anos depois, em 1792, sendo destruído por um incêndio provocado por um foguete disparado durante uma festa religiosa, havia muitas apresentaçōes de espetáculos ao ar livre, especialmente na Plaza Mayor e nos terrenos baldios da cidade, espaços nos quais trabalhavam os volatineros. ${ }^{1}$

Os volatineros, que trabalhavam em grupos ou individualmente, constituem a matriz do espetáculo circense no Rio de La Plata. Estes

André Carreira é professor do Centro de Artes da Udesc e pesquisador do CNPq. Este texto foi realizado a partir de uma entrevista com a pesquisadora Beatriz Seibel em dezembro de 2005.

1 Artistas que, com habilidade e arte, andam e saltam pelo ar sobre uma corda ou arame, e fazem outros exercícios semelhantes (Diccionario de la Real Academia, Espanha). 
artistas podem ser considerados uma herança do Renascimento do Século de Ouro Espanhol, quando floresceu a arte de ambulantes, os chamados cómicos de la legua, artistas que valorizavam os gestos, a dança e os cantos. O primeiro volantinero que trabalhou em Buenos Aires foi o espanhol Blas Ladro Argandra y Martinez, que se apresentava como um especialista em maromas, ${ }^{2}$ bailes e provas de equilíbrio.

$\mathrm{O}$ volatinero era um artista multifacético, capaz de realizar acrobacias, e que também dançava os bailes tradicionais para as festas públicas, além de atuar em pantomimas e representar o "gracioso", sempre que necessário. Segundo a historiadora Beatriz Seibel, os volatineros apresentavam diversos números, tais como danças da terra, habilidades de Matemática e Física, equilíbrios, além de outros jogos de mãos e bailes (cf. Seibel, 2002, p. 42).

$\mathrm{O}$ trabalho dos volatineros quase sempre estava combinado com corridas de touros e jogos do pato, ${ }^{3}$ e as apresentaçôes se faziam mais intensas durante as festas religiosas, as quais ofereciam oportunidades para que a população saísse às ruas desfrutando de entretenimentos que davam vida à pacata cidade. A praça de touradas do bairro Monserrat, inaugurada em 1791, foi palco de diferentes apresentaçôes de volatineros. Nesse mesmo ano, tal praça recebeu a companhia de Joaquín Oláez, que fez apresentações de bonecos antes de viajar para uma turnê ao Rio de Janeiro (cf. Seibel, 2002, p. 43).

A companhia típica de volatineros era polivalente, e era comum que negros escravos participassem das mesmas, especialmente integran- do os grupos musicais que acompanhavam as apresentações com ritmos alegres e intensos a marcar o clima das proezas. Isso significava muitas vezes a incorporação de elementos das danças de origem africana como parte do entretenimento. Em várias dessas ocasiōes, os candombes $^{4}$ faziam-se presentes, apesar de serem, ainda em 1766, proibidos sem a prévia permissão das autoridades civis.

Junto a essas tradições da cultura negra, também estavam presentes, no dia-a-dia do Rio de La Plata, as improvisações e cantos dos payadores 5 e danças dos guadérios. Como afirma Seibel, o historiador Ricardo Rojas dizia que, tal como as representações dialogadas dos pastores deram origem às peças chamadas mimodias, às farsas e aos sainetes, no teatro nacional argentino, a arte dos payadores constitui-se como elemento fundador dos primitivos dramas gauchescos. Segundo Coria, nessa atividade artística e musical há também a herança indígena, já que o payador não foi originalmente urbano, mas sim rural. Além disso, deveria somar-se a influência dos negros com seus confrontos de tambores, que podiam durar horas. ${ }^{6}$

Outra figura que constituiu um elemento chave desse ambiente da Colônia foi o pregoeiro de rua. Oriundo da Idade Média, o pregoeiro era responsável pelos mais diferentes anúncios e também por uma musicalidade que caracterizava as ruas do centro da cidade. As crônicas do vice-reinado mencionam pregóes de uma infinidade de produtos que animavam a garotada, os transeuntes e todos os ambulantes que circulavam pelas empoeiradas e estreitas

2 Números com cordas.

3 Espécie de jogo a cavalo no qual se utilizava um pato como "bola" a ser arremessada em um alvo.

4 Baile de ritmo muito vivo, de procedência africana, ainda muito popular em certos carnavais da América do Sul (Diccionario de la Real Academia, Espanha).

5 Repentistas que cantavam em desafios.

6 Confrontos este que Néstor Ortiz Oderigo chama de diálogos organográficos, que terminavam quando um "combatente" deixava fora de combate ao outro (1997). 
ruas porteñas. As descrições da vida da Buenos Aires colonial nos permitem supor a importância de qualquer atividade que animasse o lento passar das horas em tempos de paz. A visita de artistas estrangeiros, que chegavam ao porto com vistas à conquista de novas praças e com a esperança de encontrar o "El Dorado", também trazia novidades e novos modos de trabalho. Aos grupos de volatineros, que chegavam diretamente da Espanha durante a segunda metade do século XVIII, somavam-se grupos que provinham do México e passavam por Buenos Aires, para posteriormente se dirigem ao Uruguai e, eventualmente, ao território brasileiro.

A primeira metade do século XIX foi de intensa transformação na história política da Argentina. Em 1806 e 1807, respectivamente, duas invasões inglesas foram derrotadas por cidadãos de Buenos Aires em armas, o que levantou os ânimos de independência contra a metrópole espanhola e culminou na Revolução de 25 de maio de 1810 e na posterior Declaração de Independência, ocorrida em 9 de julho de 1816. Um novo país surgia e se submergia em uma guerra em defesa de sua soberania. Nesse processo, a cidade crescia em importância no panorama da região.

Ao longo do século, as diversões públicas consolidaram-se, um maior número de artistas passou a circular pelos teatros e terrenos baldios e muitas famílias circenses sentaram praça na cidade. A partir da segunda década do século XIX, o crescimento das apresentações circenses em Buenos Aires é notório.

A diversão ao redor das praças de touros incluía também as brigas de galos, desfile de bonecos, mojigangas, ${ }^{7}$ apresentaçôes de gigantes e anões, além de outras estranhezas. Em 1820, as apresentações do Teatro Romano no Coliseo um espetáculo de autômatos - causaram furor pela forma como reproduziam os seres humanos. No mesmo período, a cidade teve a oportunidade de assistir a um espetáculo de "fantasmagorias", baseado em ilusões de ótica e projeções.

Apesar de todas as novidades, os espetáculos de destrezas e pantomimas continuaram a ser, todavia, os que mais impacto tinham entre a população. Os volatineros continuaram sendo as figuras mais atraentes na hora da diversão. Entre as várias companhias de volantineros que se apresentaram nesse período estavam a de Joaquín Oláez e a do italiano Francesco Orsi. Alguns volatineros, como José Cortés "o Romano" e Oláez já trabalhavam como atores no Coliseo Provisiona. Se eles apresentavam espetáculos de pantomima, ou como volatineros, também atuavam em montagens de textos espanhóis, ocasiōes nas quais se ocupavam de papéis secundários (cf. Klein, 1984).

O palhaço inglês Francis Bradley (1820) trabalhou durante seis anos no Circo Olímpico com funções permanentes, apesar de ser muito criticado por suas atuações de equitação, que foram consideradas obscenas, razão pela qual chegou a ser detido por oito dias em 1821. Bradley trabalhou nessas temporadas acompanhado por artistas criollos, que posteriormente continuaram suas carreiras pessoais (cf. Seibel, 2002). Seu trabalho com pantomimas e cenas cômicas influenciou toda uma geração de novos artistas.

Em 1830 foi criado o Parque Argentino - uma grande área no centro da cidade -, o que propiciou mais espaço para o trabalho de companhias de circo. Entre elas estiveram a de José Chiarini e a companhia francesa de Zozó Boniface, que era ator e mago, e que posteriormente se fixou no teatro-circo do Parque.

Nesse período também se realizavam muitas pantomimas que rememoravam façanhas militares. No circo dos Franconi eram apresentadas as "glórias militares", inspiradas nas histórias das vitórias de Napoleão. Em 1834,

7 Jogos com fantasias de animais e com personagens farsescos. 
apresentou-se a Compañia Ecuestre, Gimnasia y de Pantomima Laforest-Smith, que também tomava fatos históricos para suas pantomimas. Uma das particularidades dessa companhia eram as apresentações que Andrew Ducrow fazia de "quadros plásticos", nos quais eram reproduzidas estátuas famosas. Essa companhia também se destacou pela montagem de pantomimas eqüestres, além de comédias e farsas em inglês.

Outra companhia que se destacou na década de 30 do século 19 foi o Nuevo Círculo Olimpico, do norte-americano Steward. Sob a condução de Steward trabalhavam artistas locais e estrangeiros. Já em 1840, o Circo Olímpico del Jardin de Retiro realizou apresentações dos palhaços Pedro Rosso e do volantinero inglês William Brown. Nessa mesma década, o Circo Olimpico começou a apresentar no final dos espetáculos cenas divertidas, sainetes e pantomimas. Assim, o espetáculo circense ficou dividido em duas partes: na primeira, se apresentavam as destrezas e provas; na segunda, o teatro, antecipando, assim, a forma de espetáculo que se tornou comum no circo criollo no final daquele século (cf. Seibel, 2002, p. 109).

Em 1851, uma companhia circense italiana se apresentou no Teatro del Retiro com o sainete $O$ barbeiro dentista, e a companhia francesa de Eugenio Hénault ofereceu provas, pantomimas, arlequinadas e quadros vivos ao público. Como se pode notar, esse intenso movimento de espetáculos circenses e sua proximidade com certos modos da atividade teatral constituíram uma base sobre a qual nasceu, posteriormente, o espetáculo do circo-teatro argentino.

Sendo o teatro a manifestação cultural oficial mais importante da Colônia, e compreendendo a atenção que o poder governamental e eclesiástico dedicava a este, não surpreende o fato de que sobre o mesmo se exercia um forte controle de censura a o fim de se "garantir diversão sã". Isso implica em dizer que as formas espetaculares que estavam à margem da cena oficial - nas ruas, terrenos baldios, lonas de circos ou praças de touros - contavam com um pouco mais de liberdade, ao mesmo tempo em que ofereciam um maior acesso para o público comum.

Enquanto as ruas assistiam a essa variedade de espetáculos que incluía, eventualmente, até mesmo tragédias, como a montagem de Sansão apresentada em um teatro ao ar livre, em 1705, os salōes aristocráticos, os pátios de colégios e universidades tinham nas representações de peças importadas da Espanha, ou de textos que reproduziam os modelos do teatro espanhol, sua preferência.

Os espetáculos híbridos de rua, que fundiam a destreza com o humor, a representação de situaçôes dramáticas com o cômico e a habilidade física com a encenação de personagens, constituíram a matriz de uma teatralidade que rapidamente se forjou como representativa do ser nacional. É preciso lembrar que a idéia de nacionalidade, naquele período, dizia respeito a uma posição política comprometida com a separação dos elementos oriundos da Espanha. A construção da noção de uma cultura criolla pareceu necessária no processo de construção da independência política. Nesse sentido, existiram diversas ações com o fim de consolidar o espaço daquilo que, no campo cultural, poderia ser considerado como nacional.

Mesmo assim, no caso do teatro, os atores criollos trabalhavam quase sempre em sainetes e dramas de autores estrangeiros. Nessas ocasióes, predominavam, certamente, os dramaturgos espanhóis, mas autores como Voltaire, Saint-Pierre e Goldoni também eram encenados. A importância que se atribuía ao autor estrangeiro pode ser observada nos objetivos da Sociedad del Buen Gusto del Teatro, formada em 1817 com a função de aperfeiçoar o teatro como meio de educação. Essa Sociedad tinha como plataforma a proposição de peças que "emulem as de primeira ordem da Europa”. Assim, tomando a cultura da metrópole como a principal referência, os homens notáveis da cidade estimulavam as traduçôes e não descuidavam da censura, com o fim de cuidar dos bons costumes e fazer do teatro um instrumento de ilustração da sociedade. 
A presença de companhias estrangeiras e a conseqüente predominância de uma dramaturgia que não representava os anseios e os interesses de autonomia e independência perduraram além do processo de independência política. Como afirma Seibel,

o predomínio das companhias espanholas, italianas e francesas, com seus repertórios de ópera, drama, comédia, zarzuelas, opereta e varieté, se estende na Argentina, e em outros países latino americanos, assim como a moda da patinação que invade os teatros no final daquele período (Seibel, 2002, p. 195).

Desde o século XVIII, a intelectualidade criolla reivindicava uma cultura nacional, que, em se tratando do teatro, significava uma dramaturgia de autores locais. O trabalho com artistas estrangeiros foi um hábito comum que atravessou os séculos XVIII e XIX e entrou no século $\mathrm{XX}$, quando se intensificou o processo de chegada de imigrantes que alimentaria a industrialização do país.

Muitas foram, no final da primeira metade do século XIX, as iniciativas institucionais que buscaram fomentar um teatro de caráter nacional. Entre as tentativas de instalação de um teatro nacional, destaca-se a criação da Compañia Porteña-Dramática, sob orientação do ator José Maria Casacuberta, e que pode ser considerara como a maior expressão do desejo de substituição dos referentes estrangeiros. Apesar disso, o anúncio divulgado pela companhia, que propagava seu repertório, não deixava de destacar "uma brilhante coleção de peças novas da Europa" e de completar com a referência a "várias originais do país" (Seibel, 2002).

Em 1875, criou-se, por iniciativa governamental, a Escuela de Música y Declamación. Um pouco depois, intelectuais destacados estabeleceram a Sociedad Protectora del Teatro Nacional (1877), que se associou ao empresário proprietário do Teatro La Victoria com o fim de montar peças nacionais, embora o primeiro repertório não deixasse de incluir peças america- nas e espanholas. Em 1881, foi criado o Círculo Dramático Argentino com o fim de dar proteção aos autores locais. Até mesmo as medidas financeiras, que buscavam beneficiar o autor nacional, não tiveram o impacto pretendido, e só paulatinamente, com o próprio crescimento das companhias, a situação mudou. Fato decisivo para isso foi o processo de formação de novos atores criollos. Eles trabalhavam nas companhias estrangeiras como apoio, enquanto participavam nas tentativas de articulação de companhias locais.

Nesse sentido, as famílias circenses cumpriram um papel importante ao formarem constantemente novos artistas polivalentes que transitavam, sem dificuldades, nos mais diferentes gêneros do espetáculo. Seibel afirma que,

na Argentina, nas companhias de circo, que em sua maioria apresentam pantomimas, formam-se os interpretes criollos que participariam no ressurgimento do teatro nacional no século XX. Surgem novas famílias circenses criollas, e outras, francesas ou italianas, se estabelecem e adotam modalidades locais (Seibel, 2002, p. 196).

O curso do teatro argentino e de seu projeto de nacionalização se relacionam, de forma direta, com os processos políticos do país. No período das campanhas do exército contra as tribos indígenas que habitavam o deserto patagônico, na década de 1870 , se observa a implantação da rede ferroviária e a busca de interiorização do país. Nesse momento, circulam intensamente histórias e contos sobre gaúchos solitários, vítimas do autoritarismo de eventuais autoridades locais. Começa a aparecer o paradigma do herói dos pampas: solitário, rústico e bravio.

A poesia gauchesca, um gênero que se relaciona com as raízes do sentimento de argentinidade, assenta suas bases com a publicação, entre outros, do épico Martin Fierro, de José Hernández, em 1872. O mesmo autor publicou La Vuelta de Martin Fierro, em 1879, mes- 
mo ano no qual aparecera Juan Moreira, ${ }^{8}$ de Eduardo Gutiérrez, publicado no jornal $\mathrm{La}$ Patria Argentina sob a forma de capítulos, entre novembro de 1879 e janeiro de 1888. O interesse do público em histórias de heróis populares fomentou a publicação de inúmeros folhetins em jornais e de versóes em pantomimas, as quais eram apresentadas ao ar livre ou sob a lona dos circos. As pantomimas a cavalo já faziam parte do universo do espetáculo da Colônia eram vários os circos e artistas volatineros que se apoiavam em obras da literatura para construir um eixo para as performances de destrezas. $\mathrm{O}$ circo criollo utilizou os números de cavalos, tão comuns nos circos, os quais constituíam o elemento chave de suas pantomimas. Ao incorporar falas e seguir utilizando os cavalos, os Podestá inovaram. Mas, como destaca Seibel, há aqui outra herança do Teatro do Século de Ouro Espanhol, pois, na cena dos corrales, também se utilizavam cavalos.

Os Irmãos Podestá, que já haviam realizado vários sainetes cômicos, estrearam, em 1884, a pantomima Juan Moreira, com José Podestá - famoso como o palhaço Pepino 88 no personagem título. Integravam o elenco, a fim de darem maior veracidade ao espetáculo, montado com a supervisão de Eduardo Gutiérrez, vários artistas criollos. A cena estava montada de modo que as sequiências de ação e eqüestres eram realizadas no picadeiro, enquanto as cenas de interior ocorriam em um tablado que fazia as vezes de palco.

O impacto do espetáculo pode ser medido pela repercussão na imprensa da época, a qual ressaltou a interpretação de José Podestá e anunciou o "nascimento do teatro nacional" (El Diário, julho de 1884), porquanto se tratava da primeira vez que uma produção nacional chamava a atenção do público, o qual não deixou de lotar a sala do Circo Politeama. A companhia apresentou Moreira mais de dez vezes, o que já é, em si mesmo, um fato excepcional, pois o costume era o de que em uma temporada houvesse, quando muito, apenas três ou quatro apresentaçōes. Dois anos depois, após uma turnê pelo Uruguai e pelo Brasil, os Podestá criaram a Compañia Podestá-Scotti e, na cidade de Arrecifes, apresentaram novamente Moreira. Outra vez alcançaram um grande sucesso. Segundo as memórias de José Podestá, foi a partir de uma sugestão do proprietário do terreno no qual o circo estava instalado que ele decidiu transformar a pantomima em "drama falado em dois atos", dando origem ao drama gauchesco.

O circo Podestá-Scotti circulou por diferentes cidades do interior e depois foi para Buenos Aires, onde se apresentou para um público de bairro, sempre com boa resposta da audiência. Em 1887, a imprensa da cidade de La Plata destacou a qualidade da ação do espetáculo e o "sabor criollo" da representação (cf. Colombo, 1986).

Parece que o fato de o protagonista do drama criollo - José Podestá - também ter sido a grande figura da primeira parte do programa, na pele do palhaço Pepino 88, potencializava o caráter popular e localista do espetáculo. Criava-se uma forte empatia com o público, o que constituía um elemento de diferenciação com as outras modalidades de teatro. As descriçōes do trabalho realizado por José Podestá, na montagem do mimodrama que se transformou em peça teatral, destacam os detalhes das falas e da relação destas com o jogo eqüestre.

Para melhor se compreender o drama no circo criollo, é interessante considerar a original proposição da pesquisadora Beatriz Seibel, que identifica como eixo central no nascimento do drama no circo criollo a utilização da ação dra-

8 É interessante notar que em 1882 na cidade de Chivilcoy foi apresentada uma primeira montagem baseada no caso do bandoleiro Juan Moreira. Tratou-se de Juan Moreira, bandido de Matanzas, texto escrito e dirigido por Juan Arpessani com um elenco amador de italianos. 
mática implícita à pantomima. Ela seria o ponto de partida para a estruturação da dramaturgia. O texto dramático introduzido na cena por José Podestá tratava da "verbalização" da ação que os atores da pantomima realizavam. Esse texto transformava em palavras aquilo que os atores realizavam fisicamente em cena. Desse modo, Podestá utilizou o elemento que dava sustentação às pantomimas para transformá-las em dramaturgia, e alcançou uma nova forma de produção textual, que permitia uma cena mais natural do ponto de vista da interpretação. Podestá dedicou-se a fixar essas palavras não pronunciadas a partir dos diálogos do folhetím e também transformou algumas narrações de Gutiérrez em seqüências de diálogos. Durante o processo das apresentações, o roteiro escrito por José Podestá era parcialmente modificado por força das improvisações dos atores e pelos inevitáveis ajustes no elenco, que surgiam como conseqüência das permanentes viagens da companhia. ${ }^{9}$

A articulação desse modo de representação com a busca de um realismo constituiu, do ponto de vista da ambientação, um aspecto fundamental daquele espetáculo: sua alta dose de verdade. $\mathrm{O}$ valor da interpretação mais natural, fundada no jogo do improviso próprio da tradição circense, foi um elemento chave para tornar esse espetáculo o marco de uma época.

José Podestá, ao fixar palavras e adaptar diálogos, levou o espetáculo circense à esfera do dramático, deslocando o foco da habilidade do artista para o do drama da personagem. A figura heróica do solitário gaúcho, que se desloca pelos campos abertos sobre seu companheiro eqüino, já não importa tanto pela capacidade de lidar com o elemento animal, mas pela ca- pacidade simbólica de lidar com a complexidade da vida. Essa dimensão simbólica também esteve relacionada aos sentimentos de nacionalidade que se estavam afirmando naquele período histórico.

Moreira foi o primeiro espetáculo de caráter profundamente teatral, identificado como produto nacional, que conseguiu convocar um grande público. $\mathrm{O}$ espetáculo chamou a atenção pela qualidade naturalista da cena. $\mathrm{O}$ público e a própria crítica perceberam que a cena representava com fidelidade a vida campeira e, especialmente, a caracterização do herói solitário que, apesar de ser um bandido, é vítima das figuras do poder. A qualidade das destrezas eqüestres e a fluidez da cena nas quais os atores atuavam com segurança e profunda identificação com os tipos representados estabelecia uma empatia forte com o público, o que permitiu que a companhia representasse seguidamente aquele drama gauchesco.

Essa experiência cênica adquiriu a dimensão de referência nacional porque combinou a utilização de uma obra que parecia constituir um dado da nacionalidade com uma operação característica do ato de fundar uma nação, ou seja, a partir da fusão de referentes da cultura culta da metrópole com elementos da cultura popular.

Pela primeira vez a cena argentina recebia um espetáculo que não estava engessado pelas normas do teatro europeu e, ao mesmo tempo, que ia além das fronteiras do burlesco, apesar de ter na base de sua estrutura o fluir da vida do circo. Por isso, a encenação de Juan Moreira pode ser considerada o primeiro passo na direção de uma prática de fusão entre ele-

9 Mesmo com a incorporação de novos participantes - inclusive um artista japonês chegou a representar uma personagem campeira - o que caracterizou a encenação foi a identidade criolla. Para se ter uma idéia mais precisa da repercussão do espetáculo é interessante observar que alguns tipos surgidos na cena tornaram-se referências da cultura argentina até a contemporaneidade. Este é o caso, por exemplo, da expressão cocoliche, nascida com o personagem Cocoliche. Criação do ator Celestino Petray, que falava misturando o italiano com o espanhol, transformou-se no paradigma da fala do imigrante italiano. 
mentos cultos do teatro proveniente da metrópole e o fazer artístico popular - circense por excelência. Por isso, essa encenação é tomada, até hoje, como o marco de fundação do teatro nacional argentino. Os sentimentos nacionais que se expressaram nessa montagem confluíram com a necessidade de se estabelecer um referente nacional para a nação emergente.

\section{Referências bibliográficas}

CASTAGNINO, R. H. El circo criollo. Buenos Aires: Plus Ultra 1953.

COLOMBO, M. S. "Los primeros años del Juan Moreira en la Plata" (1886-1894), Revista del Instituto Nacional de Estudios de Teatro, Buenos Aires, t. 5, n. 13, 1986.

CORIA, J. C. Pasado y presente de los Negros en Buenos Aires. Disponível em: <www.educarargentina.com.ar/CORIA/coria15.htm>. Acesso em: outubro de 1997.

KLEIN, T. El actor en el Río de La Plata. De la Colonia a la independencia nacional. Buenos Aires: Ed. Asociação Argentina de Actores, 1984.

SEIBEL, B. Historia del Teatro Argentino (Desde los rituales hasta 1930). Buenos Aires: Corregidor, 2002.

Los cómicos ambulantes. Buenos Aires: Centro Editor de América Latina, 1982. 